\title{
MODERNIDAD Y POSMODERNIDAD \\ en el teatro argentino actual
}

\author{
Osvaldo Pellettieri \\ UBA-GETEA-CONICET-Buenos Aires
}

\begin{abstract}
RESUMEN
Jameson ha señalado que el posmodernismo en los países centrales es la dominante cultural del capitalismo tardío. Cabría entonces preguntarse qué es en Latinoamérica, en la Argentina. ¿Existirá un posmodernismo de los excluidos o, en todo caso, de los marginados de la posmodernidad? ¿Formará parte de nuestra dependencia crónica? ¿Pasará con la posmodernidad lo que ya ha sucedido con las modernizaciones que generalmente hemos aceptado acríticamente, dejando de ser lo que éramos para pasar a ser como los otros? ¿Podremos ignorarla desconociendo la creciente globalización?

En Buenos Aires ha sido acogido desde hace ya por lo menos diez años con un fuerte entusiasmo acrítico por los llamados sectores "emergentes" y con una dura resistencia por los sectores relacionados con el «teatro de arte» o "teatro social moderno".

Nos proponemos analizar la evolución de esta tendencia estético-idcológica y observar, a nivel social y teatral, su carácter indigente. En la Argentina esta condición tiene un fuertc acento historicista porque nuestro teatro siempre fue «descolocado", "periférico» y "marginal». El estudio de nuestro sistema teatral incluye sus intentos de ruptura y continuidad, por lo que, sin desdeñar los fenómenos de recepción productiva, pondremos el acento en la capacidad de nuestro teatro para generar su propia dinámica. Creemos pertinente esta aclaración porque la mayoría de los trabajos que abordan este tema lo hacen enfocando el hecho sólo desde el intertexto europeo-norteamericano, desestimando, lamentablemente, la peculiaridad de nuestro teatro.
\end{abstract}

\section{INTRODUCCIÓN}

Puede resultar esclarecedor que, a varios años de nuestros artículos sobre teatro de intertexto posmoderno ${ }^{1}$ y teatro antimoderno o premodemo ${ }^{2}$ en Buenos Aires, hagamos una suerte de síntesis de sus contenidos.

\footnotetext{
'Cuando empleamos los términos «teatro de intertexto posmoderno" en lugar de «teatro posmoderno" estamos aludiendo a la relación entre textos, a la mutua reescritura que se advierte en el texto dramático y el texto espectacular, de distintos textos del presente o del pasado. Es decir (en expresión de Barthes) que el teatro argentino actual sólo es comprensible por el juego de textos que lo precede y lo rodea.
} 
En 1989, en una conferencia que pronunciamos para The Canadian Association for Latin American and Caribean Studies (CALACS), hablábamos de emergentes textualidades antimodernas, de mezcla y de la falta de finalidad de la historia del teatro latinoamericano. Decíamos (1990:9): «Creemos también que es oportuno describir la situación actual del teatro latinoamericano en las principales ciudades de nuestro mapa teatral: a nuestro juicio se ha llegado al final de la segunda fase del sistema teatral abierto en los sesenta y ha comenzado la tercera».

Señalábamos el agotamiento del sistema viejo (el moderno), la aparición de sus textos otoñales y epigonales y de la palabra paródica como un signo de doble significación: por un lado, indicaba el desgaste de ciertos procedimientos y por otro advertía que se estaba pasando a un nuevo sistema. Decíamos también que la crisis de cambio no sólo alcanzaba al proceso dramático, sino que incluía a los procedimientos de puesta en escena y métodos de actuación (8-9).

Asimismo, poníamos de manifiesto la importancia de los textos emergentes de los ochenta en el proceso que sobrevendría: «Todos ellos tienen un punto en común frente a la marginal modernidad de nuestro continente: desde la parodia, la resistencia y el cuestionamiento, coinciden en la necesidad de revisarla» (9). En esos textos observábamos tres tendencias que caracterizábamos de la siguiente forma:

«(El teatro de la parodia y el cuestionamiento.) Su fin es polemizar abiertamente con la modernidad de los sesenta todavía dominante en Buenos Aires. Frente al teatro 'serio', cuestionador, testimonial, trata de imponer el puro juego, la búsqueda del efecto reidero (La Banda de la Risa, Los Melli, Los Macocos, Las Gambas al Ajillo, entre otros)» (9).

«(El teatro de resemantización de lo finisecular o neosainete.) Se plantea una búsqueda de la identidad no sólo desde el punto de vista temático -como lo hicieron los autores del sesenta- sino también desde el punto de vista estético (...) Dos textos en los que se advierte un cuidado purismo finisecular son El partener (1988), de Mauricio Kartun, e Y el mundo vendrá (1989), de Eduardo Rovner. En ellos se pretende resemantizar los artificios del sainete tragicómico o tragicomedia, especialmente, en cuanto a la apelación de lo caricaturesco, a lo sentimental y al principio constructivo de la reiteración, bases de los géneros populares latinoamericanos» $(9-10)$.

Observábamos, además, la aparición de un tercer modelo, el teatro de resistencia, cuya interpretación era, a nuestro juicio, básica para comprender la introducción del teatro de intertexto posmoderno en Buenos Aires:

«Seguramente del teatro de los noventa emergerá también lo que denominamos teatro de resistencia. (...) [que] lo es contra la cultura oficial y su movimiento irradiador que tendió a absorber y neutralizar a la modernidad marginal latinoamericana. Ya no pretende la ruptura del sistema teatral anterior, sino que, desde su interior, propone una nueva forma de hacer teatro sin desconocer los modelos del pasado. La recontextualización y refuncionalización del discurso moderno se construye en esta cultura de resistencia a partir de la supresión de las oposiciones forma/contenido,

\footnotetext{
${ }^{2}$ Que un teatro sea antimoderno no significa que necesariamente su intertexto sea posmoderno. Gran parte de los neosainetes o teatro de resemantización de lo finisecular y el teatro de la parodia y el cuestionamien to, siendo teatro antimoderno, no se incluyen en el teatro de intertexto posmoderno. Lo mismo sucede con algunas obras de Ricardo Monti.
} 
realismo/formalismo, cultura alta/cultura popular. Trabaja también el culto de la nostalgia, el pastiche y la palabra popular como mito (Postales argentinas, de Ricardo Bartís.)» (11).

Finalmente nos preguntábamos: «¿Qué significan los cambios enunciados? ¿Qué significa esta polémica del teatro latinoamericano que está emergiendo con nuestra moderni dad marginal de los treinta y los sesenta? Delata, a nuestro juicio, una inminente entrada a la 'propia modernidad', que se concretará quizá con la apropiación de algunas de las pautas de la posmodernidad de los países centrales. Porque, a diferencia de la modernidad marginal de los treinta y los sesenta, la modernidad de la madurez latinoamericana tendría un programa propio, una ideología estética basada en una cultura de mezcla, de cruce, de convergencia, en la cual ningún discurso sea hegemónico. Y, lo que también es importante, sabe de las limitaciones de todo proyecto que olvide nuestro pasado.» (14)

Los años transcurridos nos muestran que muchas de las audacias que perpetrábamos han sido corroboradas por el tiempo:

1. Estábamos en lo cierto cuando decíamos que asistíamos a la etapa final de la segunda fase del teatro que apareció en los sesenta. A tal punto, que hoy estamos promediando la primera fase del teatro emergente en los noventa, que podríamos denominar teatro antimoderno, siendo una de sus tendencias el de intertexto posmoderno.

2. También es verdad que en estos años se intensificó el agotamiento del sistema moderno y se produjo una amplificación de textos «otoñales» y epigonales. El teatro moderno argentino muestra poca renovación y sus teatristas «faro" van desapareciendo sin que se visualice la posibilidad de reposición. Sin embargo, el "teatro social moderno" o «teatro de arte» está lejos de ser considerado remanente por la crítica y el público: gana la mayor parte de los premios anuales de la producción, está presente en los estrenos del teatro oficial, en emprendimientos como el Ciclo Teatro Nuestro, Andamio '90 y en agrupaciones gremiales y de defensa de nuestro teatro como el MATE y SOMI, frente a un Estado empeñado en acabar con el género.

3. Por lo tanto, el que denominamos teatro antimoderno, o "sistema nuevo", no logra imponerse ni ocupar un lugar dominante, y las tres tendencias que mencionábamos más arriba han evolucionado, junto a la dramaturgia emergente que aparece en los noventa, de manera diversa. Pero, con sus peculiaridades, las cuatro son cuestionadoras -parcial o totalmente- de las modernizaciones del 30 y el 60.

4. Lo que resulta discutible y, por supuesto, no previsto, son las direcciones que ha tomado el teatro de intertexto posmoderno. Esta circunstancia es la que hace interesante, nos atreveríamos a decir apasionante, los límites de nuestro trabajo, en el que, luego de sintetizar los antecedentes de la tendencia, ubicarla en su contexto social y de observar su genealogía, sus hitos, discutiremos la tesis central de nuestro trabajo de 1989: ieste teatro emergente de intertexto posmoderno ha concretado al presente el sueño de una modernidad propia que, utilizando los procedimientos posmodernos, supere la modernidad marginal de los treinta y los sesenta y se situé lejos de cualquier domesticación oficial?

Sería igualmente importante observar si este teatro emergente ha generado en Buenos Aires formas estéticas diversas a las modernas o, simplemente, ha reciclado procedimientos modernos resemantizándolos en un contexto cultural posmoderno. 


\section{AnteCEDENTES}

En los años treinta y luego en los sesenta se produjeron las dos modernizaciones del teatro argentino (Pellettieri, 1997). Ambas dieron lugar a lo que denominamos «modernidad marginal», porque se quedó en los «bordes» de la modernidad europea, y su peculiaridad fue que no generó una vanguardia que pretendiera incluir al teatro dentro de las prácticas sociales (Bürger). Su fracaso - a diferencia de lo que ocurrió con la vanguardia teatral de los países centrales que consistió en no haber podido qucbrar la institución estética - fue parcial: triunfó al haber creado en Buenos Aires y otras ciudades el «teatro de arte», pero fue derrotada porque no pudo cumplir la utopía social que la sustentaba: cambiar la sociedad mediante la práctica teatral social. Por el contrario, a medida que pasaron los años, la crítica, los gustos del público burgués, los artistas oficiales, domesticaron el modernismo social, lo cristalizaron, restándole su actitud combativa y dejándole sólo los gestos de su antigua beligerancia.

Por otra parte, tanto en la primera como en la segunda modernización de nuestro teatro, procedimientos y tendencias tradicionales aparecieron mezcladas con los textos modernos: en los años treinta, el teatro de un dramaturgo modernizador como Roberto Arlt tiene siempre un desenlace destinado a probar una tesis realista, y durante los sesenta, realistas reflexivos y neovanguardistas no pudieron evitar que en sus discursos se infiltraran procedimientos costumbristas y hasta el realismo social del teatro de Sánchez (Pellettieri, 1997: 176-177).

Tanto en los treinta como posteriormente en los sesenta, la modernidad marginal del teatro porteño presentó como caracteres primordiales el manejo de una utopía fundamental: la destrucción de los modelos finiseculares, el cosmopolitismo, el culto a la originalidad. En esa concepción, el teatro era considerado un hecho didáctico básicamente testimonial (Pellettieri, 1990).

Con relación a su semántica, podemos establecer tres momentos en la evolución de nuestro teatro en los últimos treinta años:

1. Momento moderno existencialista: que practicó la semántica de la alienación (1960-1967). Implicó la «sublevación de la subjetividad contra la escenificación de las formas burguesas, contra las restricciones y ceremoniales arraigados en la forma de vida» (Heller). Cuestionó las limitaciones políticas y sociales de la clase media, su autosuficiencia, su alejamiento de la realidad, volcándose al trabajo, la política, la religión, las reuniones sociales, etc. Coincidió con el afianzamiento del realismo reflexivo y la neovanguardia absurdista: «señala la decadencia, la alienación, la desintegración, tanto textual como ideológica» (Pellettieri, 1997: 200).

2. Momento político: en su primera etapa, de decidido carácter optimista, practicó la semántica del fervor por los cambios revolucionarios (1967-1976). La mayor parte de sus creadores se encontraron incluidos en la militancia, ya sea en el peronismo de izquierda, ya sea en la izquierda a secas. Su textualidad revelaba «la creencia en el hecho de que el arte significaba una 'ayuda' para la sociedad en el sentido de 'curarse' de su alienación y descubría una clase 'salvadora': la popular. Se pasó de una posición de negación de la posibilidad de cambio -Soledad para cuatro (1961), de Ricardo Halac, Nuestro fin de semana (1964), de Roberto Cossa- a una limitada esperanza en las transformaciones individuales, a la rebelión contra la «vida sensata de los personajes 
de Hablemos a calzón quitado (1970), de Guillermo Gentile; Cien veces no debo (1974), de Ricardo Talesnik (1979) o Simón Blumenlstein de Germán Rozenmacher (...) Y a la confianza en las transformaciones sociales que lograría el pueblo con su dinámica y su capacidad de desenmascaramiento irónico de la burguesía, en textos como El avión negro (1970), del Grupo de Autores o Historia tendenciosa de la clase media argentina (1971), de Ricardo Monti (el teatro paródico al intertexto político)» (Pellettieri, 1997:247). Coincide con el período de intercambio de procedimientos entre los dos movimientos modernos ya enunciados: la neovanguardia absurdista y el realismo reflexivo.

En su segunda parte (1976-1985), fue el período que coincidió casi totalmente con el «Proceso de Reorganización Nacional» y se corresponde con el que hemos periodizado como Ciclo Teatro Abierto, que se constituyó en el momento canónico de la modernidad teatral argentina y su posterior transición hacia la epigonización. Comprende los textos de movimiento Teatro Abierto 1981.1985 y los que se dan entre los años 1976-1985 inscriptos en una ideología estética cercana a Teatro Abierto. Implicaron un teatro militante de cuestionamiento oblicuo al poder, con utilización de artificios teatralistas cuya finalidad era probar una tesis realista, que generalmente parodiza al poder dictatorial y sus múltiples proyecciones dentro de la sociedad (Pellettieri, 1992a).

Tanto el momento moderno-existencialista como el político consideraban el valor de la libertad como algo por lograr.

3. Momento de intertexto posmoderno: de carácter en general pesimista, presenta algunas variantes: gusta de la ironía y elude la denuncia. Reigadas (116) ha observado este momento, que va de 1985 a 1997, con gran perspicacia crítica como un período nacional posproceso «de arrepentimiento y desencanto - pero también desde el temor y el horror por lo vivido- se ha sustituido la toma de partido por el hombre nuevo, la revolución y el Tercer Mundo, por el neoiluminismo democrático o por la creciente despolitización de tonos posmodernos».

Creemos que el movimiento de cambio ya está presente en nuestro sistema teatral, en su autonomía y dinámica propia (Pellettieri, 1995: 66). A partir de este concepto, apreciamos que ya en los años setenta se produce el cuestionamiento a la modernidad marginal. En Buenos Aires tiene lugar un movimiento de deconstrucción del teatro moderno que se ve interrumpido en 1976 por la dolorosa diáspora que causa en nuestro campo intelectual (como en otras áreas) el proceso militar. Este proceso de deconstrucción anticipa nuestro teatro de los ochenta y los noventa. A fines de los sesenta aparecen espectáculos de este tipo como Fuego asoma (1969) de José María Paolantonio y Luis Verdi, con dirección del primero, en el Centro de Experimentación Audiovisual Torcuato Di Tella, que era ya un teatro de mezcla en el que se fundían el canto, la danza, la música, el cine, lo teatral, con fines satíricos sociales y estéticos.

Un caso muy claro es el de las creaciones colectivas como Porca miseria, estrenada en agosto de 1975 por el Grupo Teatro-Circo integrado por Hernán González, Lorenzo Quinteros, Tina Serrano y Rubén Szuchmacher. Porca miseria era un texto espectacular antecedente del teatro de la parodia y el cuestionamiento, que impugnaba al "teatro serio», que trabajaba con la estilización y la parodia del texto espectacular del sainete y el grotesco criollos. En la búsqueda del efecto teatral histriónico-caricaturesco no desdeñaba la maquieta y el chiste verbal y parodiaba los tics del teatro moderno. Era, al 
mismo tiempo, una feroz sátira al contexto social. La mezcla de géneros era ya su principio constructivo (Pellettieri, 1989: 89).

Caída la dictadura, se produce un renacimiento del cuestionamiento a esa modernidad marginal, que se relaciona con los cambios en el contexto social (aceptación de la democracia liberal, la desaparición del enemigo representado por el Proceso Militar). Este cambio obedece a necesidades internas: se ha mezclado con algunos elementos de la semántica del posmodernismo (cuestionamiento de la historia «como relato verdadero», adhesión al teatro de resistencia, culto de la nostalgia, la ironía y la ambigüedad) y en menor medida con procedimientos de la misma tendencia: gusto por la parodia, asunción de la cultura de mezcla, inclusión del simulacro como base de la representación.

En otro sentido, siempre alrededor de la situación actual de nuestro teatro, es importante aclarar que "teatro posmoderno" es una expresión poca usada en el campo intelectual de Buenos Aires, especialmente por los creadores. Creemos que, por lo menos entre nosotros, no hay elementos suficientes para calificar a tal actor, director o autor de posmoderno, a pesar de que ya han pasado alrededor de diez años desde la aparición de ese intertexto en nuestro teatro (Pellettieri, 1996: 65-67).

Incluso podemos afirmar que desde mediados de los ochenta hasta los noventa no se producían en nuestra ciudad textos dramáticos de intertexto posmoderno. Con la aparición de las piezas de Daniel Veronese y Rafael Spregelburd, entre otros, esta ausencia se fue parcialmente limitada. Hasta ese momento existían sólo puestas que respondían a ese modelo por la forma en que los directores utilizaban los textos dramáticos.

Para una acabada comprensión del teatro a que nos referimos, es de fundamental importancia la descripción del contexto social con la mediación del campo intelectual en que dicho teatro se produce.

En un trabajo anterior (Pellettieri, 1995) nos referíamos con relación a este aspecto, a un trabajo de Dotti. Creemos que muchas de esas ideas siguen explicando de manera cjemplar el fenómeno de nuestra vida social. Dotti señala varios hechos:

1. En la Argentina, la vida cotidiana está incluida en la posmodernidad, que califica como «indigente», porque «denota el atraso y marginalidad respecto de la condición del primer mundo».

2. En ella, lo hegemónico es lo mercantil porque está «en los núcleos semánticos básicos que conforman la convivencia social o el imaginario colectivo y configuran formas de vida». Hoy, en medio de un creciente desmejoramiento socioeconómico del país, del que son claras pruebas los despidos masivos con el consiguiente desempleo, la caída del salario, la recesión y las protestas populares, para la opinión pública la convertibilidad (un peso = un dólar) sigue siendo la garantía «contra el desastre «. Es decir, lo mercantil cumple una función estructurante; porque desde lo mercantil «descienden» los criterios de comportamiento juzgados como «deseables», racionales» y «transmisibles».

3. En la convivencia social argentina se ha desterrado el concepto moderno de crisis: "(esto) no quiere decir que no ocurran conflictos, situaciones de violencia, problemas graves y novedosos en su profundidad. Pero lo posmoderno de nuestra realidad es que estos datos son categorizados por la opinión mayoritaria, como meras disfuncionalidades de una dinámica de mercado, aún no totalmente lograda, que los ha de eliminar cuando se vigorice (...) Hoy prevalecen así, la aceptación indiferente (no sin 
cierto descrédito) de 'los políticos' y el 'parlamentarismo', pero la confianza es en el libre 'mercado' como en la estrella polar hacia la cual dirigir los esfuerzos para superar el atraso argentino, con prescindencia de los costos sociales del programa en marcha" (7-8).

4. Como conclusión, Dotti señala un hecho con el que coincidimos plenamente: «El éxito relativo del plan económico neoliberal no es la causa sino el efecto de un cambio profundo de los criterios de sociabilidad con que el sentido común y la opinión pública generalizada, entiende su propia realidad. Cambio que se sustenta en lo que se ha llamado la función hegemónica de lo mercantil en el imaginario social de los argentinos». (8)

Por lo tanto, se puede afirmar que así como con la segunda modernidad aparece en Buenos Aires el desarrollo de la tecnología, el ascenso al gobierno de la clase media individualista, el crecimiento de las ciencias sociales, la afirmación del cine arte, en fin, la aparición de una nueva metáfora del país y su relación con el mundo y sus habitantes, el teatro de intertexto posmoderno se da a conocer de la mano de la función hegemónica de lo mercantil, del menemismo, del libre mercado, de la desintegración de la sociedad: proletarización de la clase media, lumpenización del proletariado, limitación del estado de bienestar, crisis de la sociedad del trabajo, advenimiento de una intensa instrumentalización cultural desde el poder económico que maneja a discreción el mensaje informativo dirigido al público.

Frente a estas nuevas reglas de convivencia de la vida social, en el seno del teatro porteño surgen, fundamentalmente, dos tipos de actitudes. Las dos tendencias, contratiamente a lo que ocurría antes de 1976, coinciden en aceptar el liberalismo político como base para la convivencia argentina, pero se oponen al crudo liberalismo económico vigente. En esta situación, se produce una «polémica oculta entre un grupo de autores, directores y actores dominante dentro del sistema teatral -que representa la modernidad y cuya ideología podríamos denominar «antiposmoderna» (utilizando el término de Jameson) - y una seric de experiencias emergentes que denominamos de intertexto posmoderno. Trataremos de caracterizas estas posiciones.

1. Moderna realista: incluye a la mayor parte del teatro porteño dominante, que se afirmó en los sesenta, que tuvo una etapa de intercambio de procedimientos entre realistas y absurdistas en los setenta y cuyo protagonista más notable fue Teatro Abierto en los años ochenta. Esta tendencia todavía ocupa - a pesar del agotamiento estético que ya señalamos - un lugar central en el campo intelectual correspondiente al teatro a través de la hegemonía que mantiene en los gustos del público, la crítica periodística y la investigación teatral. El grupo más activo está nucleado en la Fundación Somi (apócope del nombre del desaparecido autor Carlos Somigliana), que integran algunos de los principales dramaturgos modernos: Roberto Cossa, Eduardo Rovner, Bernardo Carey, Osvaldo Dragún, Carlos Pais, Roberto Perinelli, Marta Degracia. Su actitud en el medio es canonizadora y legitimante. Dentro de esta estética, en los últimos tiempos se estrenó una serie de espectáculos se integran de manera militante a esta tendencia. Su exponente fundamental en 1997 fue «Teatro Nuestro», en el que se incluyeron autores de esta tendencia (Carlos Gorostiza y Roberto Cossa), actores (María Rosa Gallo, Pepe Soriano, Lito Cruz, Cipe Lincovsky, Juan Carlos Gené, Ulises Dumont, Alicia Zanca) y directores (Rubens Correa, José María Paolantonio, Roberto Castro). 
Las puestas de las piezas (con sus singularidades y variaciones dentro del modelo) presentan también una serie de características formales y semánticas distintivas, que le «responden» al posmodernismo -a su estética y su semántica-intensificando su sentido. A nivel de la estructura superficial o intriga sostienen una adherencia a la tesis realista concretada siempre alrededor de la utopía social e individual, la creencia en la necesidad y racionalidad de los hechos históricos y de las crisis como «momentos de verdad» del proceso social, demostrada a partir de un claro desarrollo dramático. Este desarrollo dramático se concreta en varios hechos centrales:

a) El texto dramático sigue siendo fundamental para la puesta.

b) Dicho texto es «respetado» por el director y está absolutamente controlado por éste. La obra dramática es cerrada y autosuficiente.

c) La tesis realista es reiterada en la mirada final de la representación, cerrando el sentido. Implica siempre una visión cuestionadora y didáctica sobre la vida social argentina. Una buscada valoración ideológica del mundo que cuestiona la posmodernidad indigente.

d) La puesta funciona como un todo homogéneo muy preciso, en el que predomina la noción de totalidad, una teatralidad visible y, además, «un desarrollo coherente» que le permite al público extraer sus conclusiones; es totalmente referencial.

e) Se fundamenta en una idea absolutamente comunicacional objetivista de la relación público-espectáculo.

f) Presenta un predomino total de la interpretación ideológica y política en todos los núcleos del espectáculo: producción, circulación y recepción.

g) Los textos y las puestas están construidos a partir de la certeza de que «no necesita del pasado«. Entablan con él una relación intertextual irónica, de oposición. Es el caso de Cocinando con Elisa (1997), de Lucía Laragione y la «comedia blanca» argentina de los años treinta.

h) Es un teatro comprometido ideológica y políticamente.

2) De intertextualidad posmoderna: rechaza la palabra moderna realista, mostrando en sus textos espectaculares que ha dejado de ser «verosímil» y «teatral». Utiliza algunos procedi-mientos del posmodernismo europeo y norteamericano, pero, fundamentalmente, coincide con la semántica de sus textos.

Esta tendencia se divide en dos corrientes:

a) El teatro de resistencia: esta dirección estético-ideológica tiene como paradigmas los espectáculos que Ricardo Bartís dirigió desde Postales argentinas (1988): Hamlet (1991), adaptación del texto de Shakespeare, Muñeca (1994), adaptación de la pieza de Armando Discépolo y El corte (1996). En estos textos espectaculares se aprecia una versión ambigua de la realidad social, ya que se proponen la deconstrucción de la puesta moderna pero recuperan algunos de sus procedimientos. De esta forma, crean un modelo teatral en el que el discurso moderno se refuncionaliza a partir de la supresión de las oposiciones forma-contenido, realismo-formalismo y cultura alta-cultura popular (Pellettieri 1992b).

Se parte del concepto de que la modernidad teatral argentina es un proyecto incumplido y se intenta sustraer al teatro de su domesticación. Su resistencia, expuesta especialmente en Postales argentinas y El corte, lo mismo que los metatextos de Bartís ${ }^{3}$, se

\footnotetext{
${ }^{3}$ Es interesante analizar algunos de los metatextos de Bartís y relacionarlos con sus textos y el contexto social. Son de una asombrosa coherencia (Bartís; Cruz-Pacheco, 1997ª?).
} 
encuentran dentro de un contexto social concreto del presente argentino y su resistencia se ejerce contra la cultural oficial.

En Postales argentinas se advertía ya que su director no había abandonado la idea del teatro crítico, sino que pretendía redefinirlo desde la posmodernidad. Cuestionaba, en el manejo de los actores y de la intriga (por incompletos y carentes de síntesis entre lo moderno y lo tradicional), a las modernizaciones de los treinta y los sesenta. Rechazaba de ellas su rotunda negación del pasado, su apelación a la modernización constante y, al cabo, elitista. La propuesta de Postales argentinas objetaba la racionalización y la estandarización de «lo nuevo» como banalización de la cultura. Al mismo tiempo, la aparición de Postales argentinas con su concepto deconstructivo, con su manejo de la contaminación textual, señaló el advenimiento del intertexto posmoderno en nuestro teatro.

Jencks (97) postula para la arquitectura posmoderna nociones que pueden emplearse para acercarse al teatro de Bartís: es bifronte, es decir, mira simultáneamente en dos direcciones: «hacia los códigos tradicionales de evolución lenta y a los significados étnicos particulares de su entorno y hacia los códigos cambiantes de la moda y el profesionalismo». Una actitud típica de los grandes renovadores de la modernidad cumplida, que nunca pudo lograr nuestra modernidad marginal.

El resto de su teatro mantiene el gesto de oposición a la modernidad marginal, pero también cuestiona el clima de derrota de la posmodernidad indigente. Su pesimismo se limita constantemente y esta limitación se fundamenta en su revalidación y resemantización del teatro popular argentino.

Hay una intención de acercarse a la modernidad plena en el cruce de lo nuestro y lo ajeno que, evidentemente, para Bartís es algo por lograr, y que aparece en Hamlet y en Muneca. En esta última se evidencia un intento de deconstrucción del teatro discepoliano que consiste en advertir aspectos que no habían sido considerados en las puestas y las críticas de la obra: su machismo, por ejemplo. Su puesta restituye sentidos del texto que fueron «suprimidos" por la arrogancia totalitaria de la razón. Muñeca, en versión de Bartís, implica la asunción de la incertidumbre de la crítica, la investigación y los propios teatristas, frente a un texto que tenía garantizada la certeza.

Una vuelta de tuerca muy interesante se produjo en la producción de Bartís y su grupo, el Sportivo Teatral de Buenos Aires, con El corte. En ella la contextualización referencial, mezclada con procedimientos posmodernos, resulta ejemplar para describir la estética del director. En este caso seguiremos la crítica que nuestros discípulos del GETEA (Grupo de Estudios de Teatro Argentino e Iberoamericano) hicieran de este espectáculo, y que compartimos (Nuevos Espacios): es difícil no ver reflejada en la carnicería de El corte la triste posmodernidad indigente de nuestro país: una familia que repite enfermizamente escenas traumáticas de nuestro pasado. Sin duda, la trama naturalista con funcionalidad posmoderna quiere ajustar cuentas con el pasado argentino: «Los padres castigan en el cuerpo del hijo su propia inoperancia, sus carencias simbólicas» (52). Para El corte es fundamental «diseñar formas artísticas que permitan recuperar críticamente nuestro pasado y construir otras identidades posibles» (53). Existe en el texto una profunda señal de cuestionamiento a la "letra" del realismo argentino, a su apego enfermizo a las palabras. Las carencias de su estética se aprecian en las reflexiones del tipo «no se convence a nadie con fábulas panfletarias» (53). 
Resulta evidente que el teatro de resistencia quiere mostrarnos que, en todo caso, nuestra posmodernidad es peculiar pero participa del advenimiento de los nuevos tiempos, de la crisis de la modernidad.

La propuesta de estos textos espectaculares es la de tomar al posmodernismo «desde nosotros «, con nuestras limitaciones y perplejidades, desde lo que podríamos denominar «nuestra pobreza», e intentar asimilarlo a nuestra identidad. Desde esa suerte de patetismo incontenible de Postales argentinas que le permite dialogar con otros grandes momentos de nuestro teatro, desde Arlt, desde Discépolo. Lo común en estas fases del teatro argentino es que en ellas todo es pobre, como nuestra vida en ciudad. Por eso este teatro, no dudamos, cuestiona nuestra posmodernidad indigente, y es evidente que textos como Postales argentinas y El corte, desde su intertexto posmoderno, «más que constituir una tendencia específica de pensamiento e investigación han contribuido a desafiar, reformular y enriquecer los análisis de la modernidad» (García Canclini: 19).

b) El teatro de desintegración ${ }^{4}$. Los paradigmas de esta estética son el autor y director Rafael Spregelburd [Destino de dos cosas o de tres (1993), Cucha de almas (1992), Remanente de invierno (1995), La tiniebla (1994), Raspando la cruz (1997), entre otras], el director Rubén Szuchmacher [Música rota (1994), basada en tres textos de Daniel Veronese, Palomitas blancas (1998), Polvo eres (1997), de Harold Pinter, entre otras muchas] y, muy especialmente, el dramaturgo y codirector de El Periférico de Objetos, Daniel Veronese [Crónica de la caída de uno de los hombres de ella (1960), Cámara Gesell (1993), Circonegro (1996) y El líquido táctil (1997), entre otras].

Ellos, junto a otros creadores, están protagonizando desde los primeros años de la presente década una «nueva entrada al mundo» del teatro argentino. En un ambiente limitado durante mucho tiempo a «vivir con lo nuestro» teatralmente, ellos han realizado una recepción productiva y hecho circular en nuestro sistema teatral el intertexto de una serie de autores fundamentales en la escena de hoy como Heiner Müller, Philippe Minyana, Valere Novarina y el poeta Raymond Carver. Su teatro es el resultado de una mezcla muy productiva de estos intertextos con el teatro neovanguardista del absurdo, cuyo último exponente «moderno» tardío apareció en los sesenta y entre cuyos militantes se contaban Griselda Gambaro, Eduardo Pavlovsky, Jorge Petraglia y Roberto Villanueva.

Ese teatro de la desintegración es, a nuestro juicio, la continuidad estéticoideológica del absurdo, como éste, a su vez, era la continuidad de la tradición irracionalista-pesimista del grotesco. La diferencia estriba en que el absurdo pretendía demostrar la absurdidad de la existencia humana en la sociedad; creía en la noción de sentido, exigía una interpretación, fortalecía aún la significación.

El teatro de la desintegración toma del absurdo lo abstracto del lenguaje teatral y la disolución del personaje como ente psicológico, pero no pretende demostrar nada, cree que el sentido del texto, que es absolutamente arreferencial, lo debe aportar casi en forma exclusiva el espectador. El personaje sólo «dice» el discurso, está deconstruido y psicológicamente desintegrado. El universo de este teatro es un universo no sólo sin ilusión, sino que también se nos aparece como atravesado por una mengua vertical de los afectos, de las pasiones. Todo esto, dentro de lo fragmentario de la intriga, que

\footnotetext{
${ }^{4}$ Para un estudio de la dramaturgia de Daniel Veronese y Rafael Spregelburd nos remitimos a Pellettieri, 1998.
} 
contrasta con la ilusión de totalidad de los textos de la neovanguardia y que repercute en la concepción de la puesta en escena.

El pesimismo de este tipo de teatro es profundo. Se podría decir que estos autores trabajan, especialmente Veronese, con una estética del nihilismo. Es un teatro que no se avergüenza de su elitismo, que rechaza la chatura de nuestra sociedad, sus cultores son hábiles polemistas, contradictorios, despectivos y esgrimen razones suficientes para cuestionar la banalidad de nuestro fin de siglo. Como en el caso de Bartís, sus metatextos guardan gran coherencia con sus textos (Cruz-Pacheco, 1997b; Weinschelbaum; ChaerPacheco).

Este teatro mostrador de la desintegración, de la incomunicación familiar, del feroz consumismo, la violencia gratuita, la ausencia de amor de la «convivencia posmoderna», es también intertextual con el contexto social, con el neoconservadorismo menemista que ha rota con las normas de la vida social. Es el emergente de nuestra posmodernidad indigente. La respuesta a todo esto es el simulacro estético perfecto: eclecticismo combinado con antiestética e ilusiones modernas que se observan en los textos y en los metatextos en el sentido de considerarse a sí mismos como radicalmente innovadores. Esto merece una explicación: ya dijimos que son conscientemente contradictores. Son antivanguardistas porque rechazan la preocupación básica de la vanguardia, que todavía está presente en el teatro de resistencia: la de crear un arte nuevo en una sociedad alternativa; pero negando a la vanguardia pretenden ser el centro de la experimentación. Al mismo tiempo, evitan reflexionar en torno a los problemas que está acarreando al teatro y a la sociedad argentina el agotamiento del modernismo, del "arte por el arte", del teatro comunitario, siendo ésta una de las características que los distinguen de los creadores del teatro de resistencia.

En este sentido es importante aclarar que otra de las diferencias es que este teatro es un teatro de autor, cuyo director considera el texto dramático como guión, mientras que el teatro de resistencia trabaja sin texto previo, como un teatro de creación colectiva, orientada por el director.

Sintetizando, el teatro de desintegración no está preocupado por recuperar aspectos del teatro moderno. Es evidente que para sus cultores estamos en un momento de cambio total dentro del sistema teatral: la modernidad teatral argentina "ya fue» $y$, por supuesto, no se puede esperar de ella ningún "proyecto incumplido». Es por ello que no les preocupa criticar la realidad, puesto que para ellos el teatro popular, al igual que el llamado «teatro culto", sólo es útil para la mezcla. No se lo desecha, sino que se lo disuelve en la deconstrucción de estilos, utilizándolo para hacer "otra cosa».

Las piezas de estos autores se ubican cerca del monólogo, ya que los personajes mantienen escasa o nula conexión entre sí. El texto semeja un cascarón vacío, es atemporal y presenta pocas referencias espaciales. Es autorreferencial, es decir, utiliza de artificio «De la plenitud verbal de un lenguaje autónomo en cuanto que permite sistemáticamente lo imposible»(Krysinski). De este modo, «el principio de incongruencia subvierte la 'comunicación correcta', involucra el uso del shock, la sorpresa, lo fantástico y lo absurdo. Da como resultado la destrucción de la referencialidad mimética y la autonomía del texto dramático».

Cabría entonces afirmar que hoy el teatro de la desintegración es el exponente más posmoderno de la escena porteña. 
Es importante para cerrar esta parte del trabajo, hacer algunas referencias sobre Szuchmacher, ya que la mayor parte lo expuesto se aplica, básicamente, a la poética de los autores. Sin duda, Szuchmacher encarna un nuevo tipo de director de escena, ya de vuelta de las arbitrariedades geniales de los «señores de la escena « -en palabras de Pavisy más cerca de la noción de «mediador» entre los distintos componentes del ensayo. Es evidente que en esta concepción, el director ha perdido responsabilidad global en beneficio de su responsabilidad técnica. La dirección se ha descentraliza y ha producido una mayor participación de los actores y demás integrantes del circuito teatral.

Aun dirigiendo textos del denominado teatro de resistencia como La china (1995), de Sergio Bizzio y Daniel Guebel, o la ya mencionada Palomitas blancas, curiosamente un texto realista reflexivo, moderno, marginal hasta la médula, Szuchmacher consigue que la puesta cuestione el culto a la interpretación del receptor. Frente a la mirada interesada del "antiposmodernimo", o la visión crítica de la modernidad que postula el teatro de resistencia, sus puestas pretenden rescatar una visión «imparcial» del texto. En ellas no encontramos «evidencia de sentido», son neutrales, el receptor puede, o no, atribuirles un sentido. La teatralidad queda oculta por el comentario de los hechos, por lo indeterminado. La dirección se mantiene en la superficie, no remite nunca a la "profundidad». Hace algún tiempo Szuchmacher nos dijo que algunos de sus trabajos implicaban «una puesta sin concepto«. Estamos de acuerdo: él deja hacer, deja hablar a los personajes, no hay en sus trabajos una mirada totalizadora. Sin llegar a la concepción nihilista o deconstruccionista de la comunicación teatral (De Marinis), propone un relativismo integral o radical que «relega a un segundo plano los significados teatrales y la comprensión intelectual del espectáculo, privilegiando de una manera unilateral los procesos perceptivos y emotivos de los espectadores".

Sus trabajos entrañan una versión ambigua del texto y de su autorreferencialidad, y generalmente a través de una irónica reproducción de formas de convivencia que no son tales, intensifica los «lugares de indeterminación" de los textos que pone en escena. Sin duda, Szuchmacher es un director que ha encontrado su camino en el teatro de desintegración.

\section{Caracteres comunes a ambas tendencias}

De todas maneras, tanto el teatro de resistencia como el teatro de desintegración participan de un cambio fundamental dentro de nuestro sistema teatral. Es por eso que resulta importante, después de exponer sus diferencias, señalar sus puntos en común:

1. La idea de la puesta en escena como un simulacro. Así, el texto no adhiere a la oposición verdadero-falso propia de la modernidad teatral.

2. La puesta busca la deconstrucción del lenguaje y de la razón y, por lo tanto, de la certidumbre. Indaga en la trama de diferencias de un texto hasta llegar a su deconstrucción.

3. La conclusión es que ambos tipos de teatro se oponen al dogmatismo de la razón. Infieren que en los textos hay varios sentidos y que la pregunta debe permanecer abierta. En este caso hay una notoria limitación de la evidencia de sentido.

4. Esta situación hace que el espectáculo se presente como fragmentario, inconcluso, complejo. 
5. El texto y la puesta son intertextuales. La relación intertextual no se establece con un texto individual, como ocurría con la intertextualidad moderna, sino con un género o tendencia.

6. No se persigue la originalidad, se escribe lo viejo (una farsa, un vodevil, etc.) Pero de una nueva manera. La vieja textualidad adquiere nuevo sentido gracias al nuevo texto.

\section{CONCLUSIONES}

Avanzada ya la primera fase del teatro de intertexto posmoderno, cabría hacer un mínimo balance y un diagnóstico de su evolución. A pesar de las limitaciones mencionadas, la aparición de esa tendencia ha aportado una serie de elementos positivos:

Ha permitido que, como en todo momento de cambio, se produzca en el teatro argentino un paréntesis en el cual la escena se piensa a sí misma. El teatro de intertexto posmoderno nos ha permitido examinar «de otra manera», críticamente, las textualidades modernas que hasta ayer nos satisfacían, observar sus limitaciones y adquirir mayor perspectiva va frente a ellas. Por otra parte, nos ha facilitado, en un sistema teatral tan prejuicioso y maligno con lo popular como el nuestro, advertir que la distancia entre este teatro y el «teatro de arte» ya no alcanza la relevancia que ostentaba en el pasado. Hay, además, entre nosotros, investigadores o no del teatro argentino, otra percepción de la historia de nuestro teatro: advertimos que ya ha superado la concepción lineal «progresista», única y cronológica «asentada en la verdad». La posmodernidad nos ha permitido reparar en que cada uno puede hacer «su» historia sin supuestos únicos, sin metas utópicas que vuelvan a inducirnos a creer que el teatro «va a salvar el país». Estamos superando los determinismos, asumiendo las limitaciones de la función del crítico y del historiador.

En cuanto a los interrogantes formulados en la introducción, cabe agregar que sólo el tiempo dirá si se concretará en la segunda fase del sistema teatral del teatro de intertexto posmoderno una modernidad plena (la posición del teatro de resistencia), si nos introduciremos totalmente en la posmodernidad (la posición del teatro de desintegración) o si, como ocurrió hasta ahora en nuestra escena, triunfará la constante histórica del realismo.

Ya en 1989 nos lo planteábamos: «No podemos asegurarlo, porque el futuro del teatro argentino consistirá en ir haciéndose. De cualquier forma, tenemos bastante confianza en que los enfoques sobre el presente teatral argentino sean acertados, porque a partir de ellos hemos establecido las hipótesis sobre el futuro." (Pellettieri, 1990:14). 


\section{RESUMO}

Jameson diz que o pós-modernismo nos países centrais corresponde à dominante cultural do capitalismo tardio. Caberia então perguntar o que é o pós-modernismo na América Latina e na Argentina. Existirá um pós. modernismo dos excluídos ou, em todo caso, dos marginais da pós-modernidade? Fará parte de nossa dependência crônica? Acontecerá com a pós-modernidade o que já aconteceu com as modernizaçōes que geralmente aceitamos acríticamente, deixando de ser o que éramos para sermos como os outros? Poderemos ignorá-la desconhecendo a crescente globalização?

Em Buenos Aires o pós-modernismo foi acolhido, há pelo menos dez anos, com um forte entusiasmo acrítico pelos chamados setores «emergentes» e com uma dura resistência pelos setores relacionados com o «teatro de arte» ou o «teatro social moderno».

Propomos analisar a evolução dessa tendência estéticoideológica e observar, a nível social e teatral, seu caráter indigente. Na Argentina, essa condição tem um forte tom historicista porque nosso teatro sempre foi «descolocado", "periférico" e "marginal». O estudo de nosso sistema teatral inclui suas tentativas de ruptura e continuidad. Sem desdenhar dos fenômenos de recepção produtiva, enfatizaremos a capacidade de nosso teatro de gerar sua própria dinâmica. Acreditamos ser pertinente esse esclarecimento porque a maioria dos trabalhos que abordam esse tema o fazem enfocando o eixo a partir do intertexto europeu-norteamericano, desprezando, lamentavelmente, a peculiaridade de nosso teatro.

\section{PALAVRAS - CHAVE}

teatro argentino, modernidade, pós-modernidade

\section{BIBIIOGRAFÍA}

BARTIS, Ricardo, 1996. «Problemáticas y perspectivas de la experimentación estética en teatro actual«, Teatro XXI, II, 3, (Buenos Aires, primavera): 18-20.

Büger, Peter, 1987. Teoría de la vanguardia. Barcelona: Península.

Chaer, S. y Carlos Pacheco, 1993. "El teatro argentino no se hace cargo de su contemporaneidad «, en La Maga, (Buenos Aires, 15 de febrero): 40-42.

Cruz, Alejandro y Carlos Pacheco, 1997a «Ricardo Bartís. Maestro de actores«, en La Maga, (Buenos Aires, 26 de febrero): 10-12.

Cruz, Alejandro y Carlos PACHECO, 1997b, «Rafael Spregelburd. Actor/dramaturgo/ director», en La Maga, (Buenos Aires, 5 de marzo): 14-15.

De MArinis, Marco, 1986. «Problemas de semiótica teatral: la relación espectáculoespectador«, Gestos, I, 1 (California, abril): 11-24.

DoTTI, Jorge, 1993. "Nuestra posmodernidad indigente «, Espacios de crítica y producción, 12 (Buenos Aires, junio-julio): 3-8. 
Fowler, Alastair, 1971. «The Life and Death of Literary Forms «, New Literary History, II, 2 (Winter) 39-75, 199-216, 213-214.

Frye, Northon, 1977. Anatomía de la crítica. Caracas: Monte Avila.

García Canclini, Néstor, 1992. «Después del posmodernismo: la reapertura del debate sobre la modernidad «, en Imaginarios urbanos. Buenos Aires: Eudeba.

Heller, Agnes, 1987/88. "Los momentos culturales como vehículo del cambio«, en Letra Internacional, 8 (Madrid, invierno) 22.

JAMESON, Fredric, 1991. «El posmodernismo como lógica cultural del capitalismo tardío «, Ensayos sobre el posmodernismo. Buenos Aires: Imago Mundi.

Jenks, Ch.A., 1977. The Language of Posmoder Architecture. New York: Rizzoli.

KRYSINSKI, Wladimir, 1989. "La manipulación referencial en el drama moderno», Gestos, 7 (California, abril): 9-31.

Kunn, Thomas S. 1962. The Structure of Scientific Revolutions. Chicago: University of Chicago Press.

Masterman, M. 1970. La crítica y el desarrollo del conocimiento. Barcelona: Grijalbo,

Pellettieri, Osvaldo, 1989. «Notas: 1975-1985: las puestas más representativas «, en La Escena Latinoamericana, 2 (Ottawa, agosto): 89-90.

Pellettieri, Osvaldo, 1990. «El teatro latinoamericano del futuro «, en Teatro argentino actual. O.Pellettieri (ed) Cuaderno del GETEA n 1, Ottawa: Girol Books-Espacio, 3-16.

Pellettieri, Osvaldo, 1992a. «El sonido y la furia: panorama del teatro de los 80 en la Argentina ", en Latin American Theatre Review, 25/2 (Kansas, Spring): 3-12.

Pellettieri, Osvaldo, 1992b «Los Macocos y el teatro nacional«, en Teatro 90. El nuevo teatro en Buenos Aires. J. Dubatti (recopilación). Buenos Aires: Libros del Quirquincho, $71-72$.

Pellettieri, Osvaldo, 1995. «Posmodernidad y tradición en el teatro actual de Buenos Aires «, en Gestos, 10, 19 (California, abril): 57-70.

Pellettieri, Osvaldo, 1996. «La puesta en escena actual en Buenos Aires«, en La puesta en escena en Latinoamérica. O.Pellettieri-E.Rovner (eds). Buenos Aires: Galerna/CITI, 65. 78.

Pellettieri, Osvaldo, 1997. Una historia interrumpida. Teatro argentino moderno (1949-1976). Buenos Aires: Galerna.

Pellettieri, Osvaldo, 1998. «Dramaturgia en Buenos Aires (1985-1995) « en La dramaturgia en Iberoamérica. O.Pellettieri-E.Rovner (eds). Buenos Aires: Galerna/ GETEA /CITI.

Reigadas, María Cristina, 1988. «Neomodernidad y posmodernidad preguntando desde América Latina ", AAVV iPosmodernidad? Buenos Aires: Biblios, 116-145.

Weinschelbaum, V. 1998. «Daniel Veronese: una mirada transversal«, en Magazin Literario, 3 (Buenos Aires, setiembre): 10-12. 